\title{
GAMBARAN PENGETAHUAN MAHASISWA TINGKAT SATU DIPLOMA TIGA REFRAKSI OPTISI TENTANG KELAINAN REFRAKSI
}

\author{
Jaja Muhamad Jabar ${ }^{1)}$, Rafhi Ghani Mahenra ${ }^{2)}$ \\ ${ }^{1,2)}$ Sekolah Tinggi Ilmu Kesehatan Dharma Husada Bandung \\ jabbar_muhammad20@yahoo.co.id \\ rafhi.ghanim@gmail.com
}

\begin{abstract}
Eyes health is the most important thing in getting visual information to do daily activities. But visual disturbance or refraction disorders, experienced by many people and it cannot be ignored because they can disturb activities. Each people need to know about those kinds of refraction disorders. That way, it is expected that people can anticipate the symptoms of this refraction disorder. Knowledge of refraction disorder such as myopia, hypermetropy, and astigmatism is important for all people, especially for people who are steeped in the field of optical refraction. The purpose of this research is to know about refraction disorders knowledge of the first grade optition refraction students. The method that used in this research is descriptive quantitative, which the data from research sample is analyzed corresponding to statistic method that being used. While the instrument is questionnaire in the form of closed questions. The population is 54 regular university students majoring in optical refraction. Result of the research shows that 38\% students in a good category, $44 \%$ students are enough and the rest $18 \%$ are in the poor category. Based on the result of the research, a solution is needed to improve students knowledge about optical refraction disorder.
\end{abstract}

Key word : eyes health, refraction disorder, optition/optical refraction.

\section{PENDAhULUAN}

Kesehatan mata merupakan salah satu syarat penting untuk menyerap berbagai informasi visual yang digunakan dalam melakukan berbagai aktivitas. Tetapi gangguan terhadap penglihatan masih menjadi masalah kesehatan di dunia termasuk di Indonesia. Gangguan penglihatan ini, atau kita mengenalnya dengan istilah kelainan refraksi merupakan penyakit mata dengan prevalensi tinggi. Adapun jenis-jenis kelainan refraksi kita mengnal ada miopia, hipermetropia, dan astigmat. Mata yang normal disebut emetropia dan akan menempatkan bayangan benda tepat di retinanya pada keadaan mata tidak melakukan akomodasi atau istirahat melihat jauh. Mata dengan sifat emetropia adalah mata tanpa adanya kelainan refraksi pembiasan sinar mata dan berfungsi normal. Sebuah pennelitian yang dilakukan oleh Indrarini (2016) terkait kelainan refraksi, dimana hasil penelitiannya ini menunjukkan bahwa :

“Angka kelainan refraksi di Indonesia, mencakup $20.7 \%$ dari seluruh penyebab kebutaan dan $25 \%$ dari seluruh penyebab gangguan penglihatan sedang dan berat. 
JURNAL SEHAT MASADA VOLUME XV

Propinsi Jawa Tengah menduduki peringkat pertama untuk perkiraan penyandang kebutaan yaitu sebesar $0,5 \%$ dari jumlah penduduk, selain itu untuk severe low vision sebesar $1.1 \%$ dari jumlah penduduk menduduki peringkat kedua setelah Jawa Timur.".

Sedangkan mengutip dari hasil hasil penelitian bagian ilmu kesehatan mata BLU RSU Prof. DR.R.D, diperoleh informasi bahwa :

"Dari 163 penderita kelainan refraksi pada anak didapatkan paling banyak menderita Miopia sebanyak 117 penderita (71,78\%), Astigmat sebanyak 41 penderita $(25,15 \%)$,sedangkan yang paling sedikit adalah Hipermetropia dengan 5 penderita (3,07\%)."

Mengacu pada dua kutipan diatas, dapat kita ketahui ternyata gangguan terhadap mata memiliki angka kejadian yang cukup tinggi. Kelainan refraksi yang tidak terkoreksi secara optimal merupakan penyebab utama penurunan ketajaman penglihatan di dunia sehingga dapat menyebabkan kebutaan. Diperlukan adanya kesadaran dari semua kalangan akan pentingnya kesehatan mata, guna menanggunglangi terjadinya gangguan mata ini. Hal ini dapat dilakukan dengan adanya kesadaran orang-orang untuk mengetahui berbagai jenis gangguan penglihatan, gejala serta akibat yang terjadi dengan gangguan penglihatan tersebut. Khususnya bagi pihak yang mendalami dalam bidang refraksi optisi, pengetahuan akan gangguan penglihatan harus menjadi pondasi dasar guna mengantisipasi terjadinya kelainan refraksi.

Dalam penelitian ini, juga dilakukan sebuah studi awal terhadap beberapa mahasiswa tingkat satu Diploma III Refraksi Optisi STIKes Dharma Husada Bandung terkait pengetahuannya terhadap gangguan mata. Dari hasil studi awal tersebut, ternyata didapat bahwa sebgain mahasiswa masih belum mengetahui apa itu gangguan penglihatan.

\section{METODE PENELITIAN}

Penelitian ini bersifat deskriptif kuantitatif yaitu untuk mengetahui seberapa tahu mahasiswa tingkat satu Diploma III Refraksi Optisi STIKes Dharma Husada Bandung tentang kelainan refarksi.

Secara garis besar, kerangka konseptual penelitian dapat dilihat pada bagan dibawah ini.

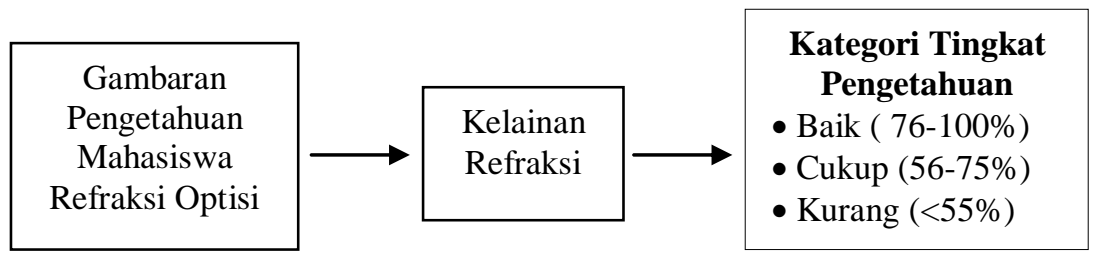

Bagan 1 Kerangka Konsep Penelitian 


\section{a. Populasi dan Sampel}

\section{Populasi}

Populasi merupakan keseluruhan objek peneliti atau objek yang akan diteliti (Notoatmodjo,2012). Dalam penelitian ini yang menjadi populasi yaitu mahasiswa tingkat satu Diploma III Refraksi Optisi STIKes Dharma Husada Bandung dengan jumlah total mahasiswa sebanyak 67 orang. Pertimbangan diambilnya populasi mahasiswa tingkat satu, hal ini mengingat mahasiswa tingkat satu baru mendapatkan perkuliahan dasar berkaitan dengan optisi yang merupakan landasan untuk materi perkulihan berikutnya.

\section{Sampel}

Sampel merupakan objek yang diteliti dan dianggap mewakili seluruh populasi. Karena adanya keterbatasan waktu, tenaga, biaya dan sebab lain (Notoatmodjo,2012). Dalam penelitian ini sampel yang diteliti mahasiswa tingkat satu sebanyak 54 mahasiswa yang memenuhi kriteria inklusi yaitu anggota populasi yang dapat dijadikan sample. Sedangkan sebanyak 13 mahasiswa termasuk kriteria eklusi, tidak memenuhi kriteria sample dikarenakan telah banyak pengalaman bekerja dalam bidang optik.

\section{b. Instrumen Penelitian}

Instrumen adalah alat ukur atau alat pengumpul data. Data yang diperoleh dari Jurnal Penelitian Kesehatan STIKes Dharma Husada Bandung suatu pengukuran kemudian dianalisis dan dijadikan sebagai bukti dari suatu penelitian (Notoatmodjo,2012). Dalam penelitian ini instrumen penelitian yang digunakan yaitu kuesioner dengan sistem pertanyaan tertutup yang terdiri dari 20 soal pertanyaan. Sebelum diberikan kepada respon yang menjadi sample penelitian, instrumen terlebih dahulu divalidasi terhadapa dua orang ahli Refraksi Optisi dengan nilai CVR 7,2 dan instrumen termasuk kategori cukup. Sedangkan untuk nilai CVI sebesar $70 \%$ dimana memiliki arti bahwa kedua Ahli Refraksi Optisi telah sepakat terhadap relevansi keseluruhan kuesioner sebgai indikator kuesioner penelitian, dengan menggunakan dasar perhitungan CVR yaitu $\{\mathrm{N},-(\mathrm{N} / 2) /(\mathrm{N} / 2)\}$.

\section{c. Prosedur Pengambilan Data}

Metode pengumpulan data dapat diartikan sebagi teknik untuk mendapatkan data ang kemudian dianalisis dalam suatu penelitian. Penelitian ini menggunakan metode pengumpulan data secara primer, yaitu data yang diperoleh atau dikumpulkan oleh peneliti secara langsung dari sumber datanya dengan memberikan kuisioner yang diberikan kepada responden dalam bentuk google form.

\section{d. Pengolahan Data}

Pengolahan data merupakan langkah penting setelah peneliti melakukan pengumpulan data, agar data mudah dimengerti dan dapat mencapai suatu tujuan. Adapun langkah-langkah pengolahan data yang akan dilakukan pada penelitian ini: 


\section{1) Checking}

Yaitu kegiatan untuk mengecek ulang data yang sudah didapat, untuk mengetahui data tersebut sudah mencapai target atau belum

\section{2) Scoring}

Jika data yang diperoleh sudah mencapai target yang ditentukan. Langkah berikutnya yaitu memberikan penskoran pertanyaan yang berkaitan dengan pengetahuan responden. Jawaban benar diberi skor 1, dan jawaban salah diberi skor 0. (Arikunto,2010)

\section{3) Processing}

Setelah dilakukan pengecekkan data dan skoring kemudian data di proses agar data yang sudah di entry ke dalam program computer (Microsoft excel dan Microsoft word). (Notoatmodjo,2012).

\section{4) Cleaning}

Yaitu pengecekan kembali data yang sudah di entry pada program computer,

apakah ada kesalahan dan ketidak lengkapan pada saat memasukan data. (Notoatmodjo,2012).

\section{e. Definisi Operasional Variabel Penelitian}

Variabel adalah sesuatu yang digunakan sebagai ciri, sifat, atau ukuran yang dimiliki atau di dapatkan oleh satuan penelitian tentang suatu konsep pengertian tertentu, misalnya umur,jenis kelamin, pendidikan, status pekawinan, pekerjaan, pengetahuan, pendapatan, penyakit, dan sebagainya (Notoatmodjo,2012). Variabel dalam peneliti ini menggunakan variabel independen, yaitu : pengetahuan terhadap kelainan refraksi, sedangkan varibel terikatnya yaitu mahasiswa tingkat satu refraksi optisi.

Tabel 1 Definisi Operasional

\begin{tabular}{|c|c|c|c|c|c|}
\hline No & Variable & $\begin{array}{c}\text { Definisi } \\
\text { Operasional }\end{array}$ & Alat Ukur & Hasil Ukur & Skala Ukur \\
\hline 1. & Pengetahuan & $\begin{array}{l}\text { Pengetahuan } \\
\text { Tentang kelainan } \\
\text { refraksi, meliputi : } \\
\text { Definisi kelainan } \\
\text { refraksi } \\
\text { Emetropia } \\
\text { Akomodasi } \\
\text { Hipermetropia } \\
\text { Ametropia } \\
\text { Myopia }\end{array}$ & Kuesioner & $\begin{array}{l}\text { Kategori tingkat } \\
\text { pengetahuan dibagi } \\
\text { menjadi : } \\
\text { 1. Baik : Skor } \\
\text { jawaban } \\
\text { responden } 76 \% \text { - } \\
100 \% \\
\text { 2. Cukup : Skor } \\
\text { jawaban } \\
\text { responden 56\% - } \\
\text { 75\% } \\
\text { 3. Kurang : Skor } \\
\text { jawaban } \\
\text { responden }<55 \% .\end{array}$ & $\begin{array}{l}\text { (Arikunto, } \\
2010)\end{array}$ \\
\hline
\end{tabular}




\section{f. Analisis Data}

Analisa data adalah pengolahan data secara manual maupun menggunakan bantuan computer. Tujuan analisis ini adalah untuk menjelaskan atau mendeskripsikan masingmasing variabel baik variabel terkait atau variabel bebas. Untuk melakukan analisan dan secara univariat digunakan distribusi frekuensi (Arikunto,2013). Dalam penelitian ini analisa data menggunakan Analisis Univariat merupakan analisa yang digunakan untuk menjelaskan karakteristik masing-masing variabel yang akan diteliti.

Dalam penelitian ini analisa univariat digunakan untuk menjelaskan atau mendeskripsikan angka atau nilai karakteristik pengetahuan responden, dengan menggunakan distribusi frekuensi. sebagai berikut :

$$
\mathrm{P}=(\mathrm{F} / \mathrm{N}) \times 100 \%
$$

Keterangan :

$\mathrm{P}:$ Persentase yang dicari

F : Frekuensi responden untuk setiap pertanyaan

$\mathrm{N}$ : Jumlah responden

\section{HASIL DAN PEMBAHASAN}

\section{a. Hasil Penelitian}

Berdasarkan hasil studi lapangan, kemudian dilakukan proses pengolahan data terhadap kuisioner dari 54 responden, didapatkan data hasil penelitian sebagai berikut:

\section{Tabel 2 Distribusi Tingkat pengetahuan mahasiswa tingkat satu tentang kelainan refraksi}

\begin{tabular}{lcc}
\hline Kategori & Frekuensi & Persentase (\%) \\
\hline Baik & 21 & $38 \%$ \\
\hline Cukup & 24 & $44 \%$ \\
\hline Kurang & 9 & $18 \%$ \\
\hline Jumlah & 54 & $100 \%$ \\
\hline
\end{tabular}

Berdasarkan tabel 1, kategori tingkat pengetahuan mahasiswa tingkat satu tentang kelainan refraksi, paling banyak kategori Cukup (44\%)

Grafik pengetahuan mahasiswa tentang kelainan refraksi dapat dilihat pada grafik berikut :

\section{Grafik 1 \\ Pengetahuan Mahasiswa tentang Kelainan Refraksi}

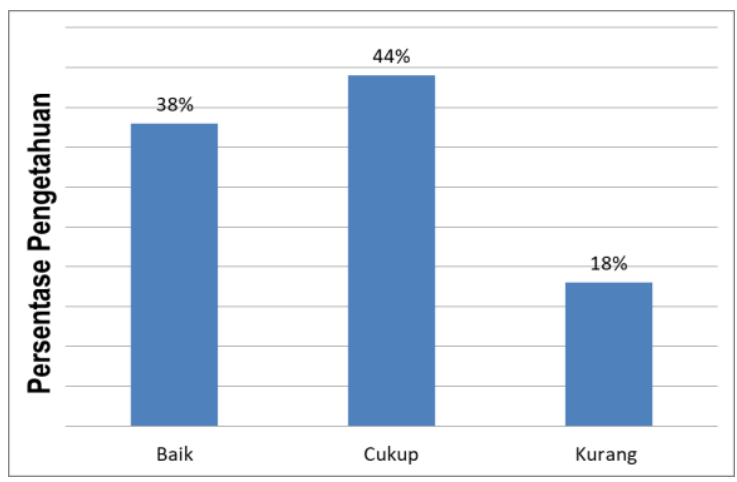

Sedangkan pengetahuan mahasiwa berdasarkan item pertanyaan soal ditunjukkan pada tabel berikut : 
Tabel 3 Distribusi Frekuensi Pengetahuan Mahasiwa Berdasarkan Item Pertanyaan Soal

\begin{tabular}{lcc}
\hline \multicolumn{1}{c}{ Pertanyaan Pengetahuan } & $\begin{array}{c}\text { Frekuensi Responden } \\
\text { Jawab Benar }\end{array}$ & $\begin{array}{c}\text { Persentase } \\
\text { Benar }\end{array}$ \\
\hline tentang pembiasan sinar pada mata & 43 & $79 \%$ \\
\hline susunan pembiasan oleh media penglihatan & 37 & $68 \%$ \\
\hline definisi Emetropia & 42 & $77 \%$ \\
\hline definisi Pungtum remotum & 36 & $66 \%$ \\
\hline definisi Myopia & 30 & $55 \%$ \\
\hline definisi Hypermetropia & 34 & $62 \%$ \\
\hline definisi Akomodasi & 43 & $79 \%$ \\
\hline definisi Ametropia & 27 & $50 \%$ \\
\hline kriteria myopia panjang bola mata anteroposterior & 36 & $66 \%$ \\
\hline definisi myopia aksial & 37 & $68 \%$ \\
\hline definisi myopia refraktif & 43 & $79 \%$ \\
\hline definisi myopia stasioner & 34 & $62 \%$ \\
\hline definisi myopia progresif & 45 & $83 \%$ \\
\hline definisi myopia maligna & 37 & $68 \%$ \\
\hline definisi hypermetropia & 46 & $85 \%$ \\
\hline definisi hypermetropia aksial & 40 & $74 \%$ \\
\hline definisi hypermetropia kurvatur & 35 & $64 \%$ \\
\hline definisi hypermetropia refraktif & 45 & $83 \%$ \\
\hline definisi hypermetropia manifes & 47 & $87 \%$ \\
\hline definisi hypermetropia laten & 38 & $70 \%$ \\
\hline
\end{tabular}

\section{Grafik 2}

Pengetahuan Mahasiswa Berdasarkan Item Pertanyaan Kelainan Refraksi

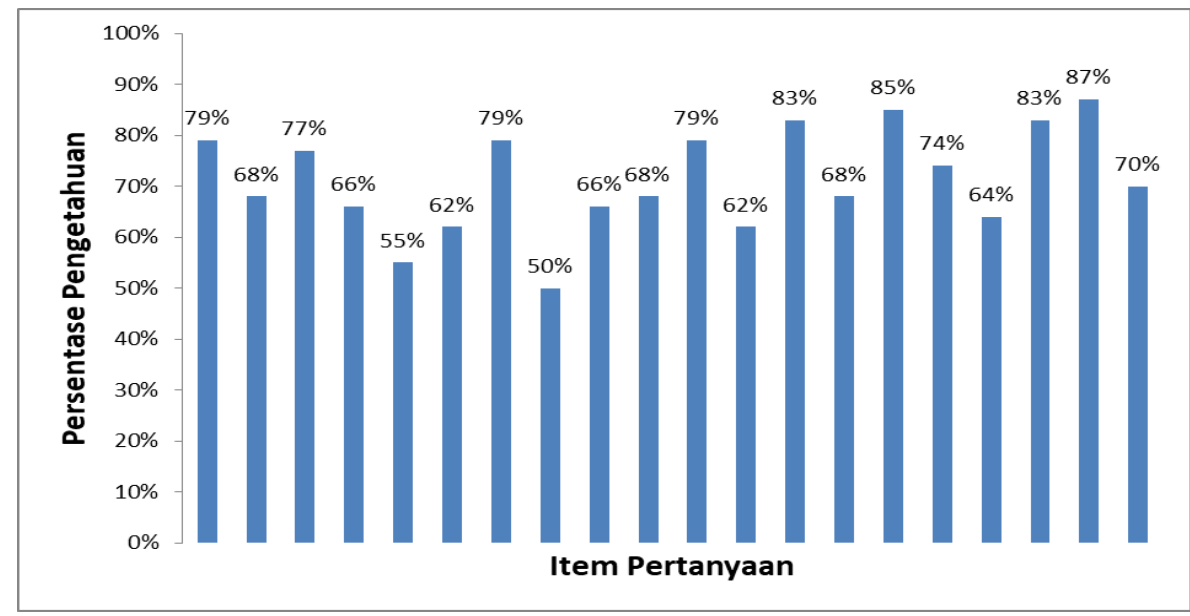




\section{b. Pembahasan}

Berdasarkan tabel 1 Distribusi Tingkat pengetahuan mahasiswa tingkat satu tentang kelainan refraksi, dapat kita ketahui bahwa pengetahuan mahasiswa terhadap kelainan refraksi yaitu sebanyak $38 \%$ termasuk kategori baik, 44\% kategori cukup, dan sebanyak $18 \%$ dalam kategori kurang. Sedangkan secara keseluruhan dari total responden, dapat diketahui pengetahuan mahasiswa tingkat satu diploma tiga refraksi optisi STIKes Dharma Husada Bandung termasuk pada kategori cukup (44\%).

Berdasarkan item pertanyaan yang diberikan pada responden didapatkan keterangan bahwa pengetahuan Mahasiswa tingkat I Diploma Tiga Refraksi Optisi Sekolah Tinggi Ilmu Kesehatan Dharma Husada Bandung, yaitu:

Mengetahui Pembiasan sinar pada mata sejumlah $79 \%$, Pengetahuan susunan pembiasan oleh media penglihatan sejumlah $68 \%$, pengetahuan tentang definisi Emetropia sejumlah 77\%, pengetahuan definisi Pungtum Remoctum sejumlah 66\%, pengetahuan definisi Myopia sejumlah 55\%, Pengetahuan definisi Hypermetropia sejumlah 62\%, Pengetahuan definisi Akomodasi sejumlah 79\%, Pengetahuan definisi Ametropia sejumlah 50\%. Pengetahuan definisi myopia panjang bola mata anteroposterior sejumlah 66\%, Pengetahuan definisi myopia aksial sejumlah 68\%, Pengetahuan definisi myopia refraktif sejumlah $79 \%$, Pengetahuan definisi myopia stasioner sejumlah 62\%, Pengetahuan definisi myopia progresif sejumlah $82 \%$, Pengetahuan definisi myopia maligna sejumlah 68\%, Pengetahuan definisi hypermetropia sejumlah $85 \%$, Pengetahuan definisi hypermetropia aksial sejumlah $74 \%$, Pengetahuan definisi hypermetropia kurvatur sejumlah 64\%, Pengetahuan definisi hypermetropia refraktif sejumlah $83 \%$. Pengetahuan definisi hypermetropia manifes sejumlah $87 \%$. Pengetahuan definisi hypermetropia laten sejumlah $70 \%$.

\section{KESIMPULAN DAN SARAN}

\section{a. Kesimpulan}

Berdasarkan hasil penelitian dan pembahasan, maka diperoleh kesimpulan :

Tingkat pengetahuan mahasiswa tingkat satu diploma tiga refraksi optisi STIKes Dharma Husada Bandung tentang Kelainan Refraksi termasuk kedalam kategori baik sebanyak $38 \%$, kategori cukup $44 \%$, dan sisanya $18 \%$ kategori kurang.

Sedangkan secara keseluruhan dari total responden, dapat diketahui pengetahuan mahasiswa tingkat satu diploma tiga refraksi 
optisi STIKes Dharma Husada Bandung termasuk pada kategori cukup (44\%).

\section{b. Saran}

Setelah melakukan penelitian, peneliti merekomendasikan beberapa hal yaitu:

1) Bagi Mahasiswa

Berdasarkan hasil penelitian ini mahasiswa tingkat satu kurang mengetahui tentang Kelainan refraksi, untuk itu diharapkan dapat menambah pemahaman tentang Kelainan Refraksi dengan membaca jurnal atau dari sumber buku lainnya yang berkaitan dengan Kelainan Refraksi.

\section{2) Untuk Penelitian Selanjutnya}

Perlu dilakukannya penelitian lain tentang faktor faktor yang mempengaruhi pengetahuan mahasiswa terhadap kelainan refraksi.

Penelitian selanjutnya diharapkan perbanyak variabel penelitian untuk mendapatkan perbandingan dan hubungan variabel juga dapat dikembangkan agar dapat menghasilkan teori konsep baru

Bagi penelitian berikutnya juga disarankan dalam penyusunan instrument lebih memperhatikan aspek-aspek berdasarkan tingkat pemahaman mahasiwa

\section{DAFTAR PUSTAKA}

Alatas \& Lusuyanti. 2001. Efek Kesehatan Radiasi Non Pegionan Pada Manusia SEMNAS. Pusat Penelitian Dan Pengembangan Keselamatan Radiasi Dan Biomedika Nuklir - BATAN: Jakarta
Amelia. 2010.Media Baru: From Noting To something, Dalam Potret Manajemen Media Di Indonesia. (Ed) Amir Effendi Siregar Dkk. Yogyakarta

American Optometric Association. 2008. people need sunglasses

Arikunto, S.2013. Prosedur Penelitian Suatu Pendekatan Praktik. Jakarta: PT. Rineka Cipta

Christy Vera Widya Wideltha. 2012. Tingkat pengetahuan keluarga tentang penyakit hipertensi di Jln Kalimantan RTO2 dan 03 RW $17 \quad$ kecamatan Pahandut Palangkaraya

Hidayat. A.A. 2014. Metode Penelitian Keperawatan dan Teknis Analisis. Jakarata: EGC

Horn. 1999. Tentang Penyinaran Metabolisme Dan Berlangsung Pada Tubuh Mahluk Hidup

Ilyas.S (2011). Ilmu Penyakit Mata. Edisi ke3. Jakarta . FKUM UI

Intan 2013. Tentang Gangguan Kesehatan Kronik Pada Kulit, Mata, Otak Sistem Imun Dan Organ. EGC. Jakarta

Isfardiyana, S. H. 2014. Pentingnya Melindungi Kulit Dari Sinar Ultraviolet Dan Cara Melindungi Kulit Dengan Sunblock Buatan Sendiri. Asian Journal Of Innovation And Enterpreneurship, 3(2), 126-133.

Istiqomah Indriana. (2016). Asuhan keperawatan klien gangguan mata. Jakarta : EGC

Kaimbo, D. K. W. (2014). AstigmatismDefinition, Etiology, Classification, Diagnosis and Non-Surgical Treatment. Astigmatism - Optics, Physiology and Management, 1(4), 59-74. https://doi.org/10.13140/2.1.2027.3607 
Komalasari, Rossa. 2015. Pengaruh Independensi, Kompleksitas Tugas, dan Gender Terhadap Audit Judgment, SNA X, 26-18 Juli 2007, Makasar

Lemeshow,S.\& David W.H.Jr. 1997. Besar Sampel Dalam Penelitian Kesehatan (terjemahan), Gadjahmada University Press, Yogyakarta

Notoatmodjo, S. (2007). Teori Perilaku. In Teori Perilaku. Jakarta : Rineka Cipta

Notoatmodjo.2012. Metodologi Penelitian Kesehatan. Jakarta. Rineka Cipta.

Priyanto, P., \& Tarwaka, P. 2016. Hubungan Tingkat Kedisiplinan Pemakaian Alat Pelindung Mata Dengan Gangguan Kesehatan Mata Pada Pekerja Las Home Industry Di Kartasura (Doctoral Dissertation, Universitas Muhamadiyah Surakarta).

Puspa, A. K., Loebis, R., \& Nuswantoro, D. (2018). Pengaruh Penggunaan Gadget terhadap Penurunan Kualitas Penglihatan Siswa Sekolah Dasar. Global Medical and Health Communication.

https://doi.org/10.29313/gmhc.v6i1. 2471

Richard, Laya, J.S.M (2014). KELAINAN REFRAKSI PADA ANAK DI BLU RSU PROF. Dr. R.D. KANDOU. Media Medika Muda. Tersedia dari url : https://ejournal.unsrat.ac.id/index.php/ecli nic/article/download/5102/4620

Riskesdas.2013 . Kesehatan Indra Prevalensi Pterygium,Kekeruhan Kornea, Dan Katarak, Secara Nasional

Rodjak, Abdul. 2006. Manajemen Usaha Tani. Jilid II. Bandung: Pustaka Gratuna

Sidarta Ilys. 2014. Ilmu Penyakit Mata Edisi Kelima. Jakarta: FKUI

Sugiyono. (2014). Metode Penelitian Kuantitatif, Kualitatif dan R\&D.

Jurnal Penelitian Kesehatan STIKes Dharma Husada Bandung 